\title{
Studies of the Effects of Co-substrates on Biodegradation Kinetics of 4-Chlorophenol Using Response Surface Methodology (RSM)
}

\author{
Abdul Halim Nurul Nornazifah, Sam Suat Peng and Ng Si Ling* \\ School of Chemical Sciences, Universiti Sains Malaysia, \\ 11800 USM Pulau Pinang, Malaysia \\ ${ }^{*}$ Corresponding author: slng@usm.my
}

Published online: 25 December 2019

To cite this article: Abdul Halim, N. N., Sam, S. P. \& Ng, S. L. (2019). Studies of the effects of co-substrates on biodegradation kinetics of 4-chlorophenol using response surface methodology (RSM). J. Phys. Sci., 30(Supp. 2), 141-151, https://doi.org/10.21315/ jps2019.30.s2.12

To link to this article: https://doi.org/10.21315/jps2019.30.s2.12

\begin{abstract}
This study aimed to investigate the effect of glucose or sucrose as cosubstrate on the kinetics of 4-chlorophenol (4-CP) biodegradation by 4-CP-acclimated activated sludge. The performance of 4-CP biodegradation was enhanced in the presence of co-substrate with greater values of zero-order rate constant observed for sucrose compared to glucose at higher 4-CP concentration. The interaction effects of two factors, namely initial 4-CP and co-substrate concentrations ranging from 100-500 $\mathrm{mg} \mathrm{l}^{-1}$ and 0-1000 $\mathrm{mg} \mathrm{l}^{-1}$, respectively, on the biodegradation kinetics were examined by using response surface methodology (RSM). For glucose, the kinetics was found dependent on the 4-CP initial concentration. The optimised condition for 4-CP biodegradation in the presence of glucose was: $200 \mathrm{mg} \mathrm{l}^{-1} 4-C P$ and $750 \mathrm{mg} \mathrm{l}^{-1}$ glucose with rate constant of $7.630 \mathrm{mgl}^{-1} \mathrm{~h}^{-1}$.
\end{abstract}

Keywords: Biodegradation, acclimated activated sludge, co-substrate, response surface methodology, kinetics

\section{INTRODUCTION}

Untreated effluent containing chlorophenols such as 4-chlorophenol (4-CP) from industries such as pesticides and oil refining sectors poses a serious threat to the receiving environment. ${ }^{1-3}$ The United States Environmental Protection Agency has listed these chlorophenols as priority pollutants in view of their high toxicity and carcinogenicity. ${ }^{3}$ Hence, proper treatment of these wastewaters is of the utmost importance before their discharge into the environment. Various physicochemical 
methods such as adsorption, extraction and photodegradation have been developed for the removal of chlorophenols. ${ }^{4}$ However, these processes involve high operating cost with secondary waste generated. ${ }^{5,6}$ Thus, biodegradation process involving the elimination of the pollutants by the metabolic activities of living microorganisms can serve as an alternative to remove such compounds. ${ }^{7}$ This process is eco-friendly and energy-efficient with achievable complete mineralisation of chlorophenols. ${ }^{8}$

Various studies on chlorophenols biodegradation using pure or mixed cultures have been conducted. ${ }^{910}$ In comparison to pure cultures, mixed cultures which contained several kinds of microorganism offered complete mineralisation of toxic compounds. ${ }^{10}$ Activated sludge process is a biological approach that employs mixed culture in treating wastewater. The performance of the activated sludge can be improved by subjecting the activated sludge to acclimation process. Enhancement of biodegradation in terms of rate and efficacy was observed after the activated sludge was pre-adapted to target toxic compound. ${ }^{9,11}$ In the study conducted by Sam et al., phenol biodegradation time decreased from 330-1260 min to $35-33 \mathrm{~min}$ at the initial phenol concentration of 25-250 $\mathrm{mg} \mathrm{l}^{-1}$ by using phenolacclimated activated sludge. ${ }^{12}$ In spite of the reported efficacy of acclimated activated sludge in removing phenolic compounds, the microorganism suffered from growth inhibition at high concentration of phenolic compounds. ${ }^{13}$

Co-metabolism is defined as the biotransformation of non-growth substrates by organism that requires an alternative source of carbon and energy for microbial growth. ${ }^{14}$ Thus, growth substrate of conventional carbon sources has been proposed to increase the tolerance of the microorganisms towards the substrate inhibition. ${ }^{6}, 15$ Addition of growth substrate has been shown to improve the biodegradation efficiency of chlorinated chlorophenols and aromatic compounds, respectively. ${ }^{15,16}$ The commonly used co-substrates are peptone, glucose and yeast extract. ${ }^{5,6}$ In the study by Loh and Tan, the enhancement of phenol biodegradation rate by yeast extract as co-substrate was dependent on the yeast extract concentration. ${ }^{6}$ To the best of our knowledge, the studies of interaction effects of co-substrate and 4-CP at various concentrations on the biodegradation performance are still limited.

Response surface methodology (RSM) is a combination of statistical and optimisation method used to assess the relationship between controllable experimental factors and observed results. ${ }^{16}$ In this study, RSM was used to examine the interaction effects of two factors, namely initial 4-CP and co-substrate concentrations on 4-CP biodegradation kinetics. It was subsequently employed to optimise the relationships between the factors and the response in the presence of different co-substrates. 
The objectives of this study are to: (1) study the effects of different co-substrate, namely glucose and sucrose, on the biodegradation kinetics of 4-CP; (2) investigate the interaction effects of co-substrate concentration and 4-CP initial concentration using RSM; and (3) optimise the 4-CP biodegradation in the presence of co-substrate.

\section{EXPERIMENTAL}

\subsection{Culturing of 4-CP-acclimated Activated Sludge}

The 4-CP acclimated activated sludge was cultured in a 1-1 sequencing batch reactor (SBR). The SBR was operated with 24 -h cycle consisting sequential stages of fill $(2 \mathrm{~h})$, react $(12 \mathrm{~h})$, settle $(1.5 \mathrm{~h})$, draw $(1 \mathrm{~h})$ and idle $(7.5 \mathrm{~h})$. The reactor was fed with the base mix containing (in $\mathrm{mg} \mathrm{l}^{-1}$ ): peptone (Merck) (32), sucrose (109), $\mathrm{KH}_{2} \mathrm{PO}_{4}$ (Bendosen) (32), $\mathrm{K}_{2} \mathrm{HPO}_{4}$ (Systerm) (180), $\left(\mathrm{NH}_{4}\right)_{2} \mathrm{SO}_{4}$ (Systerm) (212), $\mathrm{NaHCO}_{3}(\mathrm{R} \& \mathrm{M})(500), \mathrm{MgSO}_{4}(\mathrm{R} \& \mathrm{M})(49), \mathrm{FeCl}_{3} \cdot \mathrm{H}_{2} \mathrm{O}$ (18.8) (Systerm) and $\mathrm{CaCl}_{2}$ (Bendosen) (40). During fill stage, 0.61 of base mix solution was introduced into the reactor. Equal volume of treated effluent was withdrawn during the draw stage. During the acclimation period, the sucrose and peptone was gradually replaced by increasing concentration of 4-CP as the sole carbon until final 4-CP acclimation concentration of $250 \mathrm{mg} \mathrm{l}^{-1}$. The acclimated activated sludge was used for subsequent batch biodegradation studies.

\subsection{Design of Experiment using RSM}

In this study, glucose or sucrose was used as the co-substrate during the 4-CP biodegradation. For each co-substrate, the effects of independent variables, namely initial 4-CP concentration (100-500 $\left.\mathrm{mg} \mathrm{l}^{-1}\right)$ and co-substrate concentration $\left(0-1000 \mathrm{mg}^{-1}\right)$, on the response of 4-CP biodegradation kinetics were studied. The experiment design was conducted using central composite design (CCD). The experimental set of 13 runs with five replications at the design centre is shown in Table 1. The interactions between the variables with the response were analysed using Design Expert 10.0. 
Table 1: The experimental runs based on CCD design.

\begin{tabular}{rcc}
\hline Run & Initial 4-CP concentration $\left(\mathrm{mg} \mathrm{l}^{-1}\right)$ & Co-substrate concentration $\left(\mathrm{mg} \mathrm{l}^{-1}\right)$ \\
\hline 1 & 200 & 250 \\
2 & 400 & 250 \\
3 & 100 & 500 \\
4 & 300 & 500 \\
5 & 500 & 500 \\
6 & 400 & 750 \\
7 & 300 & 500 \\
8 & 200 & 750 \\
9 & 300 & 500 \\
10 & 300 & 0 \\
11 & 300 & 1000 \\
12 & 300 & 500 \\
13 & 300 & 500 \\
\hline
\end{tabular}

\subsection{Batch Biodegradation Studies}

Based on the CCD design, 500-ml reaction vessels containing nutrients, 4CP and co-substrate at different concentrations were prepared. Subsequently, $200 \mathrm{mg} \mathrm{l}^{-1}$ acclimated activated sludge was added into each reaction vessel followed by immediate aeration. At suitable time intervals, sample solution was withdrawn and filtered through Whatman No. 1 filter paper. The filtrate was analysed for the residual 4-CP, following the colorimetric 4-aminoantipyrine method at the $\lambda_{\max }$ of $504 \mathrm{~nm}$ using Shimadzu UV Spectrophotometer, until 4-CP concentration was less than $1.0 \mathrm{mg} \mathrm{l}^{-1} .{ }^{10}$ The procedure was repeated in the absence of co-substrate at various $4-\mathrm{CP}$ initial concentrations.

The kinetic data of 4-CP biodegradation was into zero-order equation:

$$
[C]_{t}=k_{0} t+[C]_{0}
$$

where $[C]_{0}\left(\mathrm{mg} \mathrm{l}^{-1}\right)$ is the initial 4-CP concentration, $[C]_{t}\left(\mathrm{mg} \mathrm{l}^{-1}\right)$ is the 4-CP concentration at time $t$ and $k_{0}\left(\mathrm{mg} \mathrm{l}^{-1} \mathrm{~h}^{-1}\right)$ is the zero-order rate constant.

\section{RESULTS AND DISCUSSION}

\subsection{Biodegradation of 4-CP}

Table 2 shows the kinetic data of 4-CP biodegradation in the absence and presence of co-substrate fitted into zero-order kinetics. In the absence of co-substrate, the $k_{0}$ values were found to decrease from $4.3809 \mathrm{l}^{-1} \mathrm{~h}^{-1}$ to $2.6904 \mathrm{mg} \mathrm{l}^{-1} \mathrm{~h}^{-1}$ when the initial 4-CP was increased from 100 to $500 \mathrm{mg} \mathrm{l}^{-1}$. At the same time, a reduction of 
biomass growth was observed (data not shown). This plausibly explain the toxicity effect of the 4-CP in deteriorating the cell growth and consequently degradation ability. ${ }^{17}$

Table 2: Kinetic parameters for zero-order 4-CP biodegradation in the absence and presence of co-substrate.

\begin{tabular}{|c|c|c|c|c|c|}
\hline \multirow{2}{*}{$\begin{array}{l}\text { Initial 4-CP } \\
\text { concentration } \\
\quad\left(\mathrm{mg} \mathrm{l}^{-1}\right)\end{array}$} & \multirow{2}{*}{$\begin{array}{l}\text { Co-substrate } \\
\text { concentration } \\
\left(\mathrm{mg} \mathrm{l}^{-1}\right)\end{array}$} & \multicolumn{2}{|c|}{ Glucose } & \multicolumn{2}{|c|}{ Sucrose } \\
\hline & & $\begin{array}{c}k_{0} \\
\left(\mathrm{mg} \mathrm{l}^{-1} \mathrm{~h}^{-1}\right)\end{array}$ & $\mathrm{R}^{2}$ & $\begin{array}{c}k_{0} \\
\left(\mathrm{mg} \mathrm{l}^{-1} \mathrm{~h}^{-1}\right)\end{array}$ & $\mathrm{R}^{2}$ \\
\hline 100 & 0 & 4.3809 & 0.9950 & 4.3809 & 0.9950 \\
\hline 100 & 500 & 7.8773 & 0.9944 & 7.5670 & 0.9954 \\
\hline 200 & 0 & 4.2526 & 0.9780 & 4.2526 & 0.9780 \\
\hline 200 & 250 & 8.0135 & 0.9756 & 6.6119 & 0.9650 \\
\hline 200 & 750 & 8.8138 & 0.9837 & 7.5699 & 0.9835 \\
\hline 300 & 0 & 4.1379 & 0.9985 & 4.1379 & 0.9985 \\
\hline 300 & 500 & 4.7202 & 0.9479 & 6.1910 & 0.9940 \\
\hline 300 & 500 & 5.8065 & 0.8765 & 6.0939 & 0.9720 \\
\hline 300 & 500 & 4.8518 & 0.9009 & 6.1165 & 0.9493 \\
\hline 300 & 500 & 4.2459 & 0.9555 & 6.3451 & 0.9986 \\
\hline 300 & 500 & 4.5919 & 0.9673 & 5.7712 & 0.9548 \\
\hline 300 & 1000 & 6.6685 & 0.9922 & 4.6980 & 0.9459 \\
\hline 400 & 0 & 4.0031 & 0.9972 & 4.0031 & 0.9972 \\
\hline 400 & 250 & 3.0807 & 0.8534 & 6.7759 & 0.9947 \\
\hline 400 & 750 & 2.5724 & 0.8895 & 7.3204 & 0.9723 \\
\hline 500 & 0 & 2.6904 & 0.9673 & 2.6904 & 0.9673 \\
\hline 500 & 500 & 1.0009 & 0.8852 & 5.1992 & 0.9533 \\
\hline
\end{tabular}

From Table 2, it is observed that the addition of sucrose improved the 4-CP biodegradation rate for all the 4-CP initial concentrations investigated. It was reported that the presence of co-substrate would increase the biomass concentration and led to higher degradation rate. ${ }^{15,18}$ However, when glucose was added as co-substrate, the enhancement of 4-CP biodegradation was only observable at the lower 4-CP concentrations of $100-300 \mathrm{mg} \mathrm{l}^{-1}$. The $k_{0}$ value deteriorated at higher 4-CP concentration of $400 \mathrm{mg} \mathrm{l}^{-1}$ and $500 \mathrm{mg} \mathrm{l}^{-1}$. At $400 \mathrm{mg} \mathrm{l}^{-1} 4-\mathrm{CP}$, the $k_{0}$ value decreased from $4.0013 \mathrm{mg} \mathrm{l}^{-1}$ to $3.0807 \mathrm{mg} \mathrm{l}^{-1} \mathrm{~h}^{-1}$ with the addition of $250 \mathrm{mg} \mathrm{l}^{-1}$ glucose. The value was further reduced to $2.5724 \mathrm{mg}^{-1} \mathrm{~h}^{-1}$ in the presence of $750 \mathrm{mg} \mathrm{l}^{-1}$ glucose. Similar observation was reported by Loh and Tan, in which better performance of phenol degradation was observed in the presence of $0.2 \mathrm{~g} 1$ to $2 \mathrm{~g}$ lyeast extract as co-substrate, however the biodegradation rate declined at higher concentration of yeast extract. ${ }^{6}$ The results from this study indicated that the effects of co-substrate on 4-CP biodegradation not only dependent on the type of co-substrate but also the concentrations of 4-CP and co-substrate. 


\subsection{Optimisation of 4-CP Biodegradation Using RSM}

For each co-substrate. the interaction effects of two variables, namely 4-CP initial concentration $\left(x_{1}\right)$ and co-substrate concentration $\left(x_{2}\right)$ on the response of $k_{0}$ value $(y)$ were analysed using CCD. The best models suggested were quadratic (Equation 2) and linear (Equation 3) for cases involving sucrose and glucose, respectively:

$$
\begin{aligned}
y= & 5.85406-7.50920+8.49290 \mathrm{E}^{-3} x_{2}-4.13500 \mathrm{E}^{-6} x_{1} x_{2} \\
& +9.26519 \mathrm{E}^{-6} x_{1}^{2}-6.37817 \mathrm{E}^{-6} x_{2}^{2} \\
y= & 10.38794-0.020626 x_{1}+1.78440 \mathrm{E}^{-7} x_{2}
\end{aligned}
$$

Analysis of variance (ANOVA) was performed to analyse the statistical significance of the regression model and its reliability. The results are presented in Tables 3 and 4. Regression coefficient with p-value below 0.05 is statistically significant. ${ }^{16}$ For sucrose, the model (Equation 2) was insignificant as evident from the failure probability of 0.2531 that is $>0.05$. Also, low values of adequate precision (5.105), $\mathrm{R}^{2}(0.5479)$ and adjusted $\mathrm{R}^{2}(0.2250)$ were exhibited. The predicted versus experimental values graph for 4-CP biodegradation in the presence of sucrose is shown in Figure 1(a). In conclusion, this model is insignificant to represent the experimental results and thus further investigation on the optimisation of 4-CP biodegradation with addition of sucrose was not conducted.

Table 3: ANOVA results of the quadratic model for 4-CP biodegradation kinetics in the presence of sucrose.

\begin{tabular}{lcccccc}
\hline Source & $\begin{array}{c}\text { Sum of } \\
\text { Squares }\end{array}$ & $\begin{array}{c}\text { Degree of } \\
\text { freedom }\end{array}$ & $\begin{array}{c}\text { Mean } \\
\text { Square }\end{array}$ & F Value & $\begin{array}{c}\text { p-value } \\
\text { Prob }>\text { F }\end{array}$ & \\
\hline Model & 7.25 & 5 & 1.45 & 1.70 & 0.2531 & Not significant \\
$x_{1}$ & 1.94 & 1 & 1.94 & 2.27 & 0.1759 & \\
$x_{2}$ & 0.57 & 1 & 0.57 & 0.67 & 0.4398 & \\
$x_{1} x_{2}$ & 0.043 & 1 & 0.043 & 0.050 & 0.8294 & \\
$x_{1}{ }^{2}$ & 0.20 & 1 & 0.20 & 0.23 & 0.6460 & \\
$x_{2}{ }^{2}$ & 3.64 & 1 & 3.64 & 4.26 & 0.0779 & \\
Residual & 5.98 & 7 & 0.85 & & & \\
Lack of fit & 5.81 & 4 & 1.94 & 43.81 & 0.0016 & Significant \\
Pure error & 0.18 & 3 & 0.044 & & & \\
Cor total & 13.23 & 12 & & & & \\
\hline
\end{tabular}

Notes: $R^{2}=0.5479 ; R_{\text {adj }}^{2}=0.2250 ;$ adequate precision $=5.105$ 
Table 4: ANOVA results of the linear model for 4-CP biodegradation kinetics in the presence of glucose.

\begin{tabular}{lrcrrrr}
\hline Source & $\begin{array}{r}\text { Sum of } \\
\text { squares }\end{array}$ & $\begin{array}{c}\text { Degree of } \\
\text { freedom }\end{array}$ & $\begin{array}{c}\text { Mean } \\
\text { square }\end{array}$ & F Value & $\begin{array}{c}\text { p-value } \\
\text { Prob }>\text { F }\end{array}$ & \\
\hline Model & 54.17 & 2 & 27.08 & 33.14 & $<0.0001$ & Significant \\
$x_{1}$ & 51.78 & 1 & 51.78 & 63.35 & $<0.0001$ & \\
$x_{2}$ & 2.39 & 1 & 2.39 & 2.92 & 0.1182 & \\
Residual & 8.17 & 10 & 0.82 & & & \\
Lack of fit & 6.81 & 6 & 1.14 & 3.33 & 0.1321 & Not significant \\
Pure error & 1.36 & 4 & 0.39 & & & \\
Cor total & 62.34 & 12 & & & & \\
\hline
\end{tabular}

Notes: $R^{2}=0.8623 ; R_{a d j}^{2}=0.8348 ;$ adequate precision $=18.594$

In contrast, the regression model for glucose (Equation 3) was significant based on a low failure probability $(\mathrm{p}<0.0001)$ and adequate precision of 18.594 . The value of the predicted coefficient (a measure of goodness of fit to the model) indicates that about $86.23 \%$ of the total variations could be explained by the model. These values showed the adequacy of the model in explaining the response. The coefficient of variation $(\mathrm{CV})$ indicates the degree of precision, in which higher reliability of the experiment is indicated by lower value of CV. ${ }^{16}$ The effect of initial 4-CP concentration $\left(x_{1}\right)$ is significant as the p-value was $<0.0001$. Whereas the effect of glucose concentration $\left(x_{2}\right)$ is not significant as indicated by the p-value $>0.05$. The $\mathrm{R}^{2}$ and adjusted $\mathrm{R}^{2}$ values are 0.8623 and 0.8348 , respectively. The predicted versus experimental values graph for 4-CP biodegradation in the presence of glucose is shown in Figure 1(b).

The perturbation plot (Figure 2) shows the comparative effects of 4-CP initial concentration $\left(x_{1}\right)$ and glucose concentration $\left(x_{2}\right)$ on 4-CP biodegradation rate. The sharp line pattern exhibited by $x_{1}$ suggests the significant effect of 4-CP initial concentration, in which increasing initial 4-CP concentration decreased the 4-CP biodegradation rate. In contrast, the almost plateau plot of $x_{2}$ indicates the less significant effect by glucose concentration. Only little increment in the rate constant was observed with increasing glucose concentration. The influence of 4-CP concentration on biodegradation kinetics is again exhibited in the 3-D and 2-D plots showing the interaction effects of factors $x_{1}$ and $x_{2}$ on $k_{0}$ value (Figure 3 ). The optimum conditions for the 4-CP biodegradation in the presence of glucose was: $200 \mathrm{mg} \mathrm{l}^{-1} 4-\mathrm{CP}, 750 \mathrm{mg} \mathrm{l}^{-1}$ glucose with $k_{0}$ value of $7.630 \mathrm{mg} \mathrm{l}^{-1} \mathrm{~h}^{-1}$. 

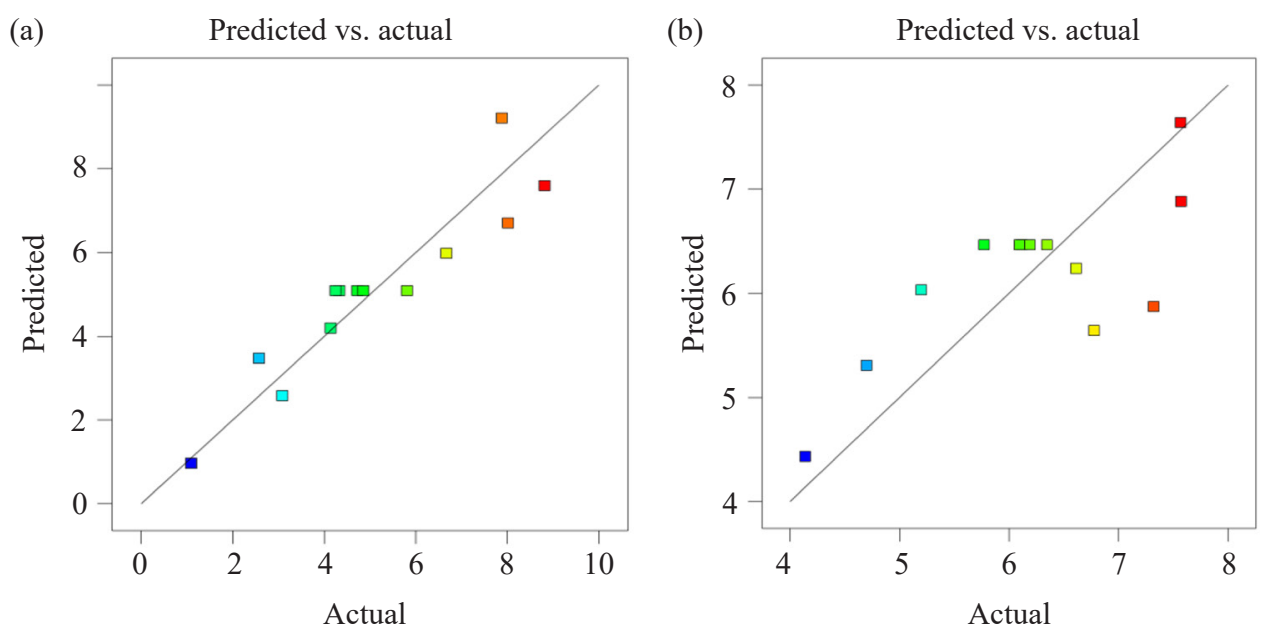

Figure 1: Predicted versus experimental results of biodegradation rate in CCD design experiments for 4-CP biodegradation in the presence of (a) glucose, and (b) sucrose.

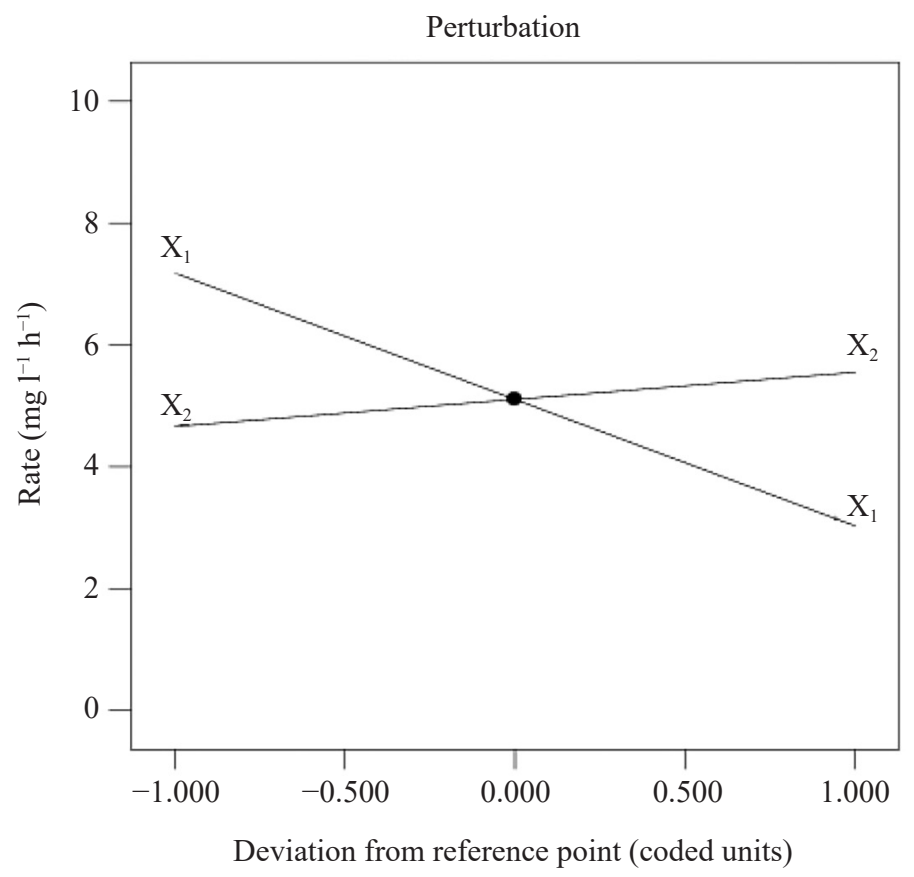

Figure 2: Perturbation plot for 4-CP biodegradation kinetics showing the effects of initial 4-CP concentration and glucose concentration. 

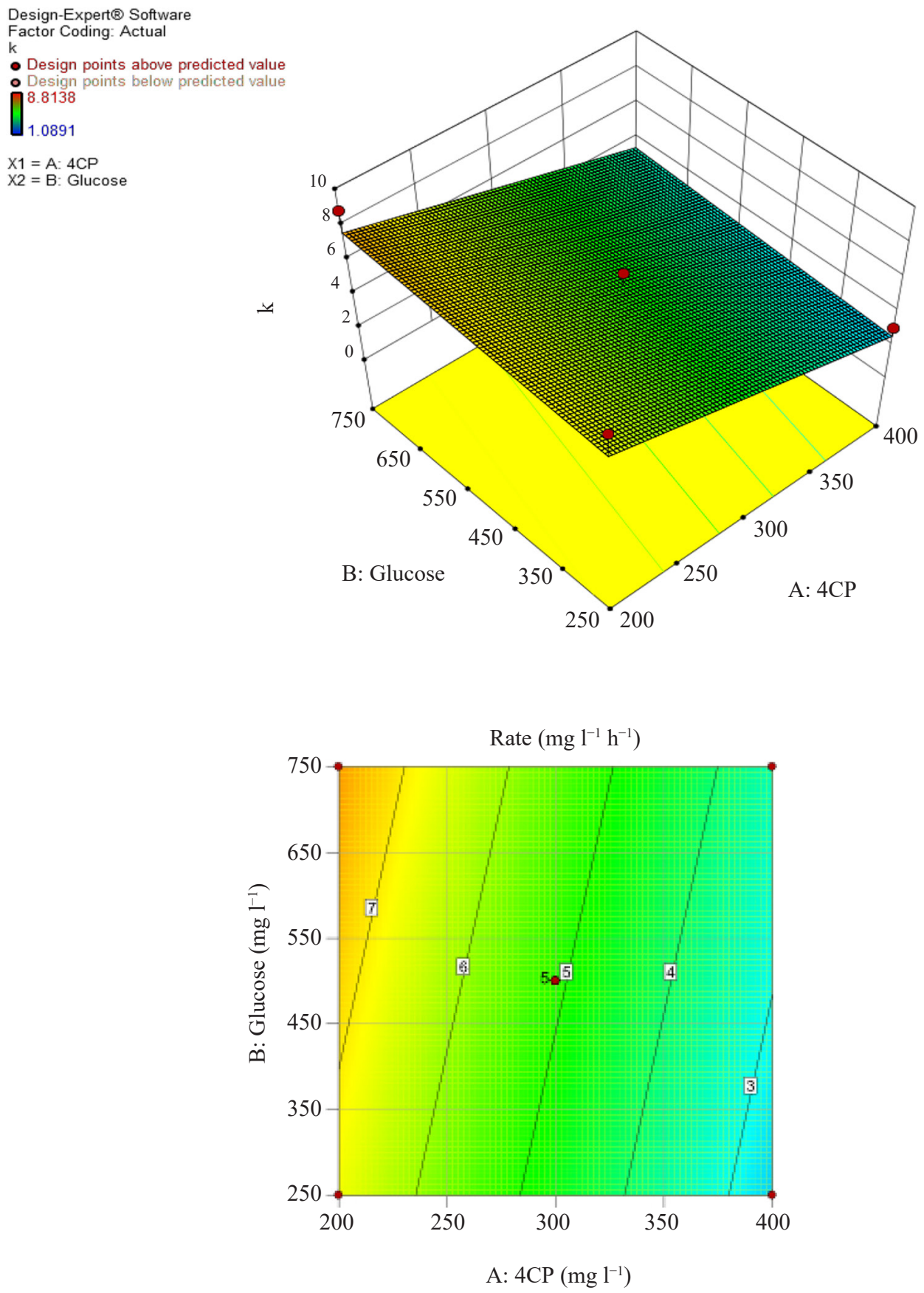

Figure 3: Three-dimensional plot and its contour plot showing the effects of initial 4-CP concentration and glucose concentration on 4-CP biodegradation rate. 


\section{CONCLUSION}

This study investigated the effect of glucose or sucrose as co-substrate on 4-CP biodegradation kinetics. The 4-CP biodegradation performance was found dependent on the type and concentration of co-substrate used. Sucrose was more effective in enhancing 4-CP biodegradation, especially at higher 4-CP concentration. From RSM analysis, the best model in relating the variables of 4-CP concentration and co-substrate concentration with 4-CP biodegradation kinetics was linear for case of glucose and quadratic for sucrose. For glucose, the 4-CP biodegradation kinetics was only dependent on the initial 4-CP concentration and the $k_{0}$ value decreased with increasing 4-CP initial concentration. The optimised 4-CP biodegradation was successfully determined for glucose as co-substrate.

\section{ACKNOWLEDGEMENTS}

Financial support from Universiti Sains Malaysia under the Bridging grant (304/PKIMIA/6316242) is gratefully acknowledged.

\section{REFERENCES}

1. Sivarajan, P., Arutchelvan, V. \& Nagarajan, S. (2016). Biodegradation kinetics of 2-chlorophenol with starch water as co-substrate using anaerobic batch reactor. Int. J. Eng. Res. Technol., 5(11), 141-145, https://doi.org/10.17577/ ijertv5is 110100 .

2. Huang, L. et al. (2013). Mineralization of 4-chlorophenol and analysis of bacterial community in microbial fuel cells. Proceed. Environ. Sci., 18, 534-539, https://doi.org/10.1016/j.proenv.2013.04.072.

3. Sahoo, N. K. et al. (2011). Biodegradation of 4-chlorophenol by arthrobacter chlorophenolicus A6: Effect of culture conditions and degradation kinetics. Biodegrad., 22(2), 275-286, https://doi.org/10.1007/s10532-010-9396-2.

4. Movahedyan, H., Assadi, A. \& Amin, M. M. (2008). Effects of 4-chlorophenol loadings on acclimation of biomass with optimized fixed time sequencing batch reactor. Iran. J. Environ. Heal. Sci. Eng., 5(4), 225-234.

5. Patel, B. P. \& Kumar, A. (2016). Multi-substrate biodegradation of chlorophenols by defined microbial consortium. 3 Biotech., 6(2), 1-10, https://doi.org/10.1007/ s13205-016-0511-x.

6. Loh, K.-C. \& Tan, C. P.-P. (2000). Effect of additional carbon sources on biodegradation of phenol. Bull. Environ. Contam. Toxicol., 64(6), 756-763, https://doi.org/10.1007/s001280000068.

7. Terreros, J. et al. (2017). Phenol biodegradation at high organic loads in a complete sludge reactor by activated sludge. ECORFAN-Bolivia J., 4(7), 42-57. 
8. Fernández, I. et al. (2013). Aerobic biodegradation of a mixture of monosubstituted phenols in a sequencing batch reactor. J. Hazard. Mater., 260, 563-568, https://doi.org/10.1016/j.jhazmat.2013.05.052.

9. Cheela, V. R. S. et al. (2014). Biodegradation of phenol using pure and mixed culture bacteria. e-J. Sci. Technol., 2(9), 91-95.

10. Sahinkaya, E. \& Dilek, F. B. (2007). Biodegradation kinetics of 2,4-dichlorophenol by acclimated mixed cultures. J. Biotechnol., 127(4), 716-726, https://doi. org/10.1016/j.jbiotec.2006.08.009.

11. Sam, S. P. \& Ng, S. L. (2017). Biodegradation of Phenol by unacclimated and phenol-acclimated activated sludge: Effects of operational factors on biodegradation efficiency and kinetics. J. Phys. Sci., 28(3), 53-67, https://doi.org/10.21315/ jps2017.28.3.4.

12. Sam, S. P., Ng, S. L. \& Rohana, A. (2018). Kinetics of biodegradation of phenol and p-nitrophenol by acclimated activated sludge. J. Phys. Sci., 29(Suppl. 1), 107113, https://doi.org/10.21315/jps2018.29.s1.14.

13. Lee, C. Y. \& Lee, Y. P. (2007). Degradation of 4-chlorophenol by enriched mixed cultures utilizing phenol and glucose as added growth substrate. World J. Microbiol. Biotechnol., 23(3), 383-391, https://doi.org/10.1007/s11274-006-9235-0.

14. Alvarez-Cohen, L. \& McCarty, P. L. (1991). A cometabolic biotransformation model for halogenated aliphatic compounds exhibiting product toxicity. Environ. Sci. Technol., 25(8), 1381-1387, htt10.1021/es00020a003.

15. Sivasubramanian, S. \& Namasivayam, S. K. R. (2014). Optimization of parameters for phenol degradation using immobilized Candida tropicalis SSK01 in batch reactor. J. Environ. Biol., 35(3), 531-6.

16. Agarry, S. E., Solomon, B. O. \& Layokun, S. K. (2008). Optimization of process variables for the microbial degradation of phenol by Pseudomonas aeruginosa using response surface methodology. Afr. J. Biotechnol., 7(14), 2409-2416.

17. Tobajas, M. et al. (2012). Enhancement of cometabolic biodegradation of 4-chlorophenol induced with phenol and glucose as carbon sources by Comamonas testosteroni. J. Environ. Manage., 95, S116-S121, https://doi.org/10.1016/j. jenvman.2010.09.030.

18. Sahinkaya, E. \& Dilek, F. B. (2005). Biodegradation of 4-chlorophenol by acclimated and unacclimated activated sludge: Evaluation of biokinetic coefficients. Environ. Res., 99(2), 243-252, https://doi.org/10.1016/j.envres.2004.11.005. 